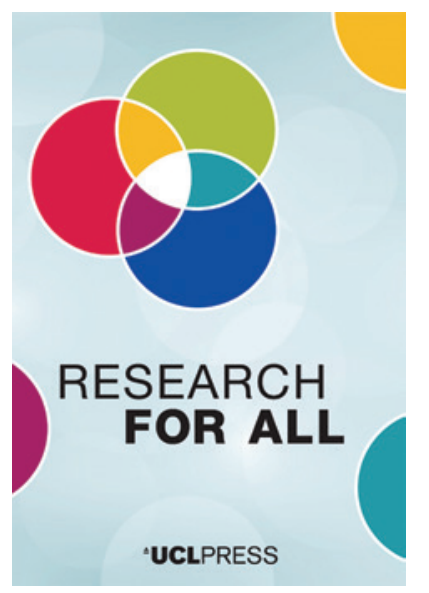

${ }^{ \pm}$CLPRESS

\section{RESEARCH FOR ALL}

The open-access journal for public engagement with research

ISSN 2399-8121 (Online)

Journal homepage:

https://www.uclpress.co.uk/pages/research-for-all

\title{
Going beyond the one-off: How can STEM engagement programmes with young people have real lasting impact?
}

Martin Archer(D), Jennifer DeWitt (D), Carol Davenport (iD, Olivia Keenan, Lorraine Coghill, Anna Christodoulou, Samantha Durbin, Heather Campbell and Lewis Hou

\section{How to cite this article}

Archer, M., DeWitt, J., Davenport, C., Keenan, O., Coghill, L., Christodoulou, A., Durbin, S., Campbell, H. and Hou, L. (2021) 'Going beyond the one-off: How can STEM engagement programmes with young people have real lasting impact?'. Research for All, 5 (1), 67-85. https://doi.org/10.14324/RFA.05.1.07

Submission date: 9 March 2020

Acceptance date: 22 September 2020

Publication date: 16 February 2021

\section{Peer review}

This article has been peer-reviewed through the journal's standard double-blind peer review, where both the reviewers and authors are anonymized during review.

\section{Copyright}

(c) 2021 Archer, DeWitt, Davenport, Keenan, Coghill, Christodoulou, Durbin, Campbell and Hou. This is an open-access article distributed under the terms of the Creative Commons Attribution Licence (CC BY) 4.0 https://creativecommons.org/licenses/by/4.0/, which permits unrestricted use, distribution and reproduction in any medium, provided the original authors and source are credited.

\section{Open access}

Research for All is a peer-reviewed open-access journal. 


\title{
Going beyond the one-off: How can STEM engagement programmes with young people have real lasting impact?
}

\author{
Martin Archer* - Imperial College London, UK \\ Jennifer DeWitt - UCL Institute of Education, UK \\ Carol Davenport - Northumbria University, UK \\ Olivia Keenan - South East Physics Network, UK \\ Lorraine Coghill - Durham University, UK \\ Anna Christodoulou - University of Essex, UK \\ Samantha Durbin - The Royal Institution, London, UK \\ Heather Campbell - University of Surrey, UK \\ Lewis Hou - Science Ceilidh, UK
}

\begin{abstract}
A major focus in the science, technology, engineering and mathematics (STEM) public engagement sector concerns engaging with young people, typically through schools. The aims of these interventions are often to positively affect students' aspirations towards continuing STEM education and ultimately into STEM-related careers. Most school engagement activities take the form of short one-off interventions that, while able to achieve positive outcomes, are limited in the extent to which they can have lasting impacts on aspirations. In this paper, we discuss various different emerging programmes of repeated interventions with young people, assessing what impacts can realistically be expected. Short series of interventions appear also to suffer some limitations in the types of impacts achievable. However, deeper programmes that interact with both young people and those who influence them over significant periods of time (months to years) seem to be more effective in influencing aspirations. We discuss how developing a theory of change and considering young people's wider learning ecologies are required in enabling lasting impacts in a range of areas. Finally, we raise several sector-wide challenges to implementing and evaluating these emerging approaches.
\end{abstract}

Keywords: impact, schools, young people, interventions, engagement programmes

\section{Key messages}

- One-off and short series of STEM interventions with young people do not appear to have the long-term impacts on aspirations that universities and other practitioners of STEM engagement are often hoping to achieve.

- Deeper programmes of engagement are required, based around theories of change and considering young people's wider learning ecology.

- Many sector-wide challenges exist to implementing and evaluating the longterm impacts of such programmes. 


\section{Introduction}

Engaging schools and young people with science, technology, engineering and mathematics (STEM) has long been a priority for STEM engagement bodies and practitioners, particularly in the cases of universities/researchers - a survey of UK researchers found that engineering and physical sciences researchers place more importance on engaging school students out of all possible publics than do researchers in other areas (Hamlyn et al., 2015). This is perhaps driven by concerns over the perceived low numbers of young people opting for studies in STEM subjects (for example, Smith, 2004). Researchers' and practitioners' motives to engage young people in order to encourage them to study a particular subject, or even to consider a particular institution - often what is meant by the terms 'outreach' and 'recruitment' respectively - are typically conflated with public engagement, which in its purest sense is formed of genuine two-way interactions for mutual benefit, and this is likely to affect their approach to engagement practice with schools (Hamlyn et al., 2015). For example, Thorley (2016) found that physicists consider engaging young people as typically transmissive (that is, one-way) in nature, and while they place high levels of importance on a range of content types and messages for young people (knowledge, excitement, relevance, careers information and so on), they unilaterally considered their own role in conveying these topics as less important. Therefore, it appears that, in general, more critical consideration is needed in recognizing audiences' needs and appropriate methods of engagement in order to improve the efficacy of raising STEM aspirations in young people.

STEM engagements with young people have generally taken the form of various one-off experiences, such as a school trip, a show, a speaker, a video or some other interaction. While popular, these are realistically limited in the types of impacts they might be able to have and the likelihood that these impacts will last in the longer term. There is evidence that one-off experiences can in the short term support content learning (probably just in the form of 'factoids'), as well as lead to affective outcomes, such as interest and inspiration (Bell et al., 2009; DeWitt and Storksdieck, 2008). Likewise, meeting a scientist can certainly provide students with an increased awareness of what a particular career involves or the range of careers that might be available, and even what courses might be required to progress (Woods-Townsend et al., 2016). Memory research, however, suggests that without further reinforcement of these learning outcomes, they are likely to be limited to days or weeks (for example, Murre and Dros, 2015). Furthermore, such one-off experiences are unlikely to have a lasting measurable effect on aspirations. Research into young people's aspirations (see L. Archer and DeWitt, 2017, among many others) highlights that aspirations are complex and multifaceted, and evolve over time. They are influenced by a range of factors, including experiences at home, in the school and in the wider community, as well as background factors that are interwoven with the way young people experience school, engagements with science, and everything else. They are also closely linked to identity - to what or who young people can see themselves becoming, and what type of person they (and others) perceive them to be. Consequently, it should not be surprising that one-off experiences, while inspirational and having potential to support a range of outcomes, are unlikely to significantly impact aspirations and educational trajectories. At the same time, because aspirations develop and are maintained (or not) over time, there can be a role for such experiences in providing additional support in their maintenance. Moreover, when considered from the perspective of learning ecologies (discussed in more detail later), any potential impact of a one-off experience 
can be extended by linking to other experiences that young people may have, both shorter term and longer in duration. In other words, while one-off experiences can be worthwhile experiences, it is important to be realistic about what they can achieve by themselves - and thus to maximize the opportunities they offer and their potential impact by linking to other aspects of young people's lives and experiences.

As we aim to move towards more impactful engagement and deeper learning, we have to carefully consider and evaluate the different types of engagement that we develop. As the sector has moved from the more didactic 'public understanding of science' towards more egalitarian constructivist approaches, we still see the dominance of traditional interventions such as lectures. We are aware of the limitations of the traditional 'listen to me' lecture-style event (for example, Freeman et al., 2014; Marbach-Ad and Sokolove, 2000; Marbach-Ad and Claassen, 2001), and in 2013, Times Higher Education noted over seven hundred studies determining that lectures were less effective than other teaching strategies (Gibbs, 2013). As such, there are definite moves in undergraduate teaching away from such traditional lecturing, with shifts in: the format of lecturing, such as segmenting and including discussion-based approaches (for example, lowa State University's Center for Excellence in Teaching, 2020); increased use of active learning strategies (for example, Durham University Centre for Academic Development, 2019); and even the redesigning of learning spaces or 'build pedagogy' (Monahan, 2002; Elkington and Bligh, 2019). However, learners and teachers will often state a preference for lectures over active learning (Deslauriers et al., 2019). Students feel that they learn more from lectures, even though the evidence suggests otherwise, perhaps partly caused by the additional cognitive effort required by active learning methods (Deslauriers et al., 2019). Against this backdrop, in trying to develop STEM public engagement projects that have greater scope to develop and support students' aspirations, we are also faced with the additional resources, costs, relationship-building and time required to make such programmes happen.

Nonetheless, several organizations and practitioners have been moving towards engagement programmes of repeated interventions with the same group of young people in order to maximize the likelihood of impacts on their aspirations towards STEM. This paper provides a landscape review and commentary aimed at STEM engagement practitioners (be they independent or based in a university or institutional setting) on some of the different approaches that have emerged, predominantly in the United Kingdom. It explores their potential benefits and limitations by drawing from evaluation literature, as well as social science and educational research/theory. Current challenges faced by the STEM engagement sector and what might be required in order to move forward effectively are also discussed. These topics arose from discussions at a session on repeated interventions at the BIG STEM Communicators Network's BIG Event 2019 (M.O. Archer et al., 2019).

\section{Short series}

The next logical step from a one-off intervention is instead to deliver a short series of interventions. Here, we discuss some different examples of such series delivered within the academic year and their evaluation thus far. We note that other programmes working on interventions across multiple years (although with only one session per academic year) are starting to emerge, but we are not yet aware of sufficient published evidence of the impacts of these types of initiatives.

Activities such as summer schools, typically run for late-secondary and sixth-form students (aged 15-18), in some sense can be thought of as a short series or 'intensive one- 
off', since they are highly focused, often into just a single week. It appears that summer schools, while enjoyable for the participants, only cause moderate changes to students' likelihood of applying to a selective university in surveys immediately afterwards (for example, Universify Education, n.d.), and many summer school programmes show no change in STEM aspirations from before to after (for example, Bhattacharyya et al., 2011; Maclver and Maclver, 2015). There is also a critical lack of longitudinal studies at present, as highlighted in a recent review of the higher education widening access sector (Robinson and Salvestrini, 2020). Such studies are necessary in demonstrating whether any increased uptake of higher education actually occurs, and whether there is causality in summer schools themselves (and not other factors) leading to improved progression. We also note that summer schools are expensive to deliver and often have severely limited places, making them highly competitive. Even with targeting of participants using widening participation criteria, they are likely to select predominantly those who are already highly bought into the subject of the summer school. This is an aspect that TASO (Transforming Access and Student Outcomes in Higher Education, https://taso. org.uk/) plans to investigate with randomized control trials in the near future.

I'm a Scientist, Get Me Out of Here (https://imascientist.org.uk/) involves an online chat between students (ages 9-18) and scientists followed by more extended Q\&A over the span of, typically, two weeks. They commissioned an evaluation using the framework of science capital to understand what impact it might be having and what might be contributing to that impact (DeWitt, 2019). Perhaps not surprisingly, one of the biggest impacts was on how young people perceived scientists - as normal, regular people, with hobbies, families and interests outside science. Such perspectives on scientists are similar to those shared by individuals with higher levels of science social capital - who know people (for example, family, friends' parents) who work in science. While there was limited evidence that this awareness completely changed aspirations of young people, there was an increased willingness among many to consider the possibility of pursuing science further. Of course, the realization of any longer-term or significant impact on aspirations is dependent on many experiences that may (or may not) happen afterwards. But this increased openness to the possibility of pursuing science, which seems to be influenced by young people realizing that scientists are people 'like me', can have a role to play.

A similar shift in perceptions of scientists was found among primary school pupils participating in Scientist of the Week, an intervention developed by the NUSTEM team at Northumbria University. This is a five-week, teacher-led intervention, in which a new scientist was 'introduced' to the students each week using presentation slides, classroom posters, and postcards to take home. In the materials provided to teachers, there was a short paragraph describing the work and life of each scientist, which included three key attributes of that person - attributes which both contrasted with stereotypical views of scientists (for example, curious, open-minded, creative) and represented characteristics that young children could imagine themselves possessing and often probably already possessed. In other words, these attributes also communicated that these scientists were 'like me'. Evaluation of this project provided encouraging evidence that young people's perceptions of scientists were shifting after the intervention, pupils were more likely to use non-stereotypical words than stereotypical words when asked to describe a scientist (Shimwell et al., under review).

L. Archer et al. (2014) report on a six-week STEM careers intervention series for Year 9 (13-14-year-old) students at a London girls' school that combined multiple activities that were co-designed and delivered by classroom teachers. The comprehensive evaluation involved before and after surveys, classroom observations, 
post-intervention student discussion groups and teacher interviews. While the series did appear to have a positive effect on broadening students' understanding of the range of jobs that science can lead to or be useful for, it did not significantly change students' aspirations or views on science.

Across the South East Physics Network (SEPnet, www.sepnet.ac.uk), two programmes targeting Year 8 (12-13-year-old) students using multiple interventions have been implemented. The first of these is the Connect Physics programme, a series of three workshops spread out across the academic year which address the following aspects:

1) What is physics? The breadth of the subject and how it all connects together.

2) Why do physics? The skills and range of careers open to physicists.

3) How do we do physics? The process of the scientific method.

The aim of Connect Physics is to raise (or at least maintain) the science capital of children at this age (L. Archer et al., 2015). An evaluation of the pilot of the programme in the academic year 2017/18 was commissioned externally. The final report (HopeStone Research, 2018) showed that the workshops were enjoyed by participants, but unfortunately the data were not robust enough to demonstrate any of the aspirational impacts that were hoped for. The key issues were that individual students' responses across the year could not be linked, and there was very little crossover between students answering the initial survey and those who answered the final one. Furthermore, responses could not be separated out by demographic information, so it was not possible to explore whether more or less impact was being had on certain groups. As the programme has become more established, further in-depth evaluation is being conducted (in the academic years 2019/20 and 2020/21). This evaluation data will allow linking of individual students' responses, exploration of themes emerging alongside demographic information, and comparisons with control data from Year 8 students at the same schools not taking part in the programme. It is hoped that this will allow a more robust assessment of the impact of this multiple intervention programme. To further support this programme, and to create the opportunity for wider reach and increased likelihood of impact lasting, SEPnet will be creating a teacher continuing professional development (CPD) programme which focuses on science capital, science identity and the aspirations of students. The aim of this is to further embed the messaging of Connect Physics into the classroom, outside the series of external interventions.

The second programme running across SEPnet (mainly supported by the University of Surrey and Royal Holloway, University of London) is Shattering Stereotypes. Its aim is to explore what role physics outreach officers can play in tackling gender stereotyping in schools. The programme was informed by the Institute of Physics (IOP) (2013) Closing Doors report into gender and subject choice and the IOP (2015) Opening Doors guide to good practice in challenging gender stereotypes in schools. Year 8 students are the primary audience, with Year 12 (16-17-year-old) students involved as session facilitators. While students enjoyed the original pilot workshops during the 2016/17 academic year and recognized the relevance of gender stereotyping (see the evaluation report of Jeavans and Jenkins, 2017), unfortunately the programme did not result in any significantly changed attitudes in before versus after surveys, either within gender or in gender variations, other than an increased feeling by both genders that physics is difficult. This latter change, however, is likely to be a common outcome over the course of Year 8 anyway (see DeWitt et al., 2019), and is therefore unlikely to be caused by Shattering Stereotypes. Following the external evaluators' recommendations, the programme was revised in 2017/18 and a second pilot was 
launched in 2018/19, going on until 2020. Shattering Stereotypes currently consists of three workshops, aiming to raise awareness of what gender stereotypes are, in the context of a student's everyday life and a student's possible career path. The project also aims to empower students so they can identify and challenge situations where they are presented with these stereotypes. The three workshops shaped around these aims, again similarly spread out across the academic year, are:

1) Gender Stereotyping \& You: Introduction to the concepts of gender stereotyping and how it can have an effect on their lives at home or at school.

2) Gender Stereotyping \& Your Career: How gender stereotyping can have an effect on a student's chosen career path, using physics as a case study.

3) Communications Challenge: Students suggest different methods of communicating issues around gender stereotyping to various target groups, including teachers, parents and younger students, giving them the opportunity to take ownership over the project.

The interventions use existing resources from the IOP and the Women in Science and Engineering campaign (for example, the People Like Me quiz). Schools are also offered options for teachers' involvement, to raise awareness of how gender stereotyping might affect their teaching. Parental engagement is also one of the programme's secondary objectives, which has proven challenging in the past, so the second pilot aims to identify new ways of including parents in the discussion. A similar approach to the revised Connect Physics evaluation is being taken with the second pilot of Shattering Stereotypes to allow for more robust analysis. Additionally, SEPnet is broadening the focus of this project to include gender stereotyping and unconscious bias CPD for teachers. A session on this has been developed and trialled, and will be offered to teachers (through partner organizations) from autumn 2020. Additionally, this CPD will collaboratively form one module of an Open University OpenLearn course being developed as a legacy of Cardiff University's Physics Mentoring Project.

The final example we present here is the Royal Institution's Ri Masterclass programme. These short series of STEM extra-curricular enrichment workshops have been running since 1981. Initially focused on mathematics at secondary level (age 13-14), it has expanded to include both primary and older age groups, as well as engineering and computer science. Teachers select students who they feel should attend. Although initially aimed at the most able, Masterclass organizers now encourage teachers to choose those they feel would benefit most. While only a few places per school are available, teachers are also encouraged to attend, and to share their experiences back at school. In 2019, 164 Masterclass series ran across the UK for 6,276 students, with over a hundred thousand students having attended since 1981. The aims of the programme (Royal Institution, 2018) have not significantly changed since its inception, and there is a correlation with some of the areas highlighted in science capital research as important in influencing students' aspirations (L. Archer et al., 2015). The main aims are to:

- improve attitudes towards, and understanding of, these subjects, their applications and their relevance in the wider world

- allow participants to explore topics interactively and in depth outside what they would see in the classroom over an extended period of engagement

- enable participants to meet a range of subject experts and enthusiasts, showcasing a variety of careers

- enable participants to meet like-minded peers from different schools across the local area. 
Evaluation has revealed some increases in confidence and positive influences on reported levels of interest in the subjects and future subject choices (Royal Institution, 2018; Barmby et al., 2008). However, these surveys were a small sample of the students involved and it has been difficult to perform meaningful longitudinal evaluation. In addition, due to the franchise model of the programme, the quality of provision can vary across the country. A significant number of students choose to attend follow-up events, however, which is positive (Royal Institution, 2018).

As with one-off interventions, a short series of engagements does appear to have some impact. However, practitioners need to be realistic as to what types of impacts are achievable from these programmes.

\section{Deeper programmes}

Research suggests that programmes with longer engagement can lead to considerable increases in students' aspirations, as well as other outcomes (Robinson and Salvestrini, 2020). These programmes often combine several different approaches in supporting and interacting with students. Here we detail a few examples.

The NUSTEM primary partnerships are an ongoing collaboration that works with children, teachers and families to support a broadening of aspirations, with a particular focus on STEM careers. There are currently 33 schools in the partnership, with about 12 having been in partnership for over five years. NUSTEM delivers regular activities in the classroom, but also supports teachers to deliver STEM career-focused activities of their own through CPD and resource development (for example, the STEM Scientist of the Week series mentioned previously), as well as working with parents and carers. Over the first three years of the partnership, the gender difference in career aspirations between girls and boys decreased significantly, with more children saying that they would be interested in a broader range of careers (Emembolu et al., 2020).

Working in partnership with several organizations, Durham University has developed a programme supporting young people in becoming science ambassadors for their own communities (www.dur.ac.uk/science.outreach/national/ambassadors/), which is adapted depending upon the needs and interests of the young people. Throughout the year-long programmes, teams of young people work together with community, university and business partners developing their own plans to work with and inspire their peers and community. This has proved successful, even in some of the most deprived areas in England. Ambassadors grow particularly in confidence as well as slightly gaining more enjoyment from presenting. While no statistically significant rises in the numbers stating that they could be a scientist in the future have occurred, schools do report increased parental engagement in science ambassador-run activities. Further work is currently under way to analyse the longer-term impact on the young people and their communities.

Urban Advantage is a formal-informal partnership between eight informal science learning institutions in New York City and the NYC Department of Education. It works with middle school students (ages 11-14) and focuses on hands-on science inquiry, supported via CPD for teachers and classroom resources, as well as visits to informal science institutions and family workshops. Recent evaluations (for example, Weinstein et al., 2014) found that participation in Urban Advantage was associated with higher attainment in science (especially among disadvantaged students) and increased student confidence in science (aspirations were not measured). Although Urban Advantage is not a UK-based initiative, we feel that it still has relevance to our overall point about the value of longer-term engagements. Additionally, there are 
limited examples in the UK (or elsewhere) of similar such initiatives, and this scarcity highlights the challenges involved in implementing them.

The Science Capital Teaching Approach (Godec et al., 2018) was developed out of the Enterprising Science project in the UK. It takes a social justice approach to science teaching, and is based on a foundation of broadening what counts (whose voices and experiences matter and have a place) in the science classroom. This approach was co-developed with 43 secondary school science teachers over four years. It is a CPD model, involving training teachers in the approach via Saturday sessions and ongoing classroom support during the year. Importantly, it was implemented in science classrooms, meaning that students experienced the approach in an ongoing fashion, over the course of a school year. Research on the approach found a statistically significant increase in the science capital score of young people whose teachers had participated in the project, as well as an increase in aspirations to study science post16 and improved attitudes to science. Teachers also reported improved behaviour and attainment (L. Archer et al., 2018).

Another CPD programme, Thinking, Doing, Talking Science, is run by Science Oxford (https://scienceoxford.com/thinking-doing-talking-science/) and works with primary school teachers over four days across the school year. It aims to support teachers in developing creative science lessons that challenge their pupils to use higher-order thinking skills and emphasizes the role of discussion in investigations and problem-solving. Evaluations of the programme found benefits to pupils' attainment, as well as attitudes, with particular benefits for girls, previously low-attaining pupils and those eligible for free school meals. As with the Science Capital Teaching Approach, evaluations of this programme highlight the benefits of experiences that extend over the course of a school year.

The Curiosity programme, led by the Wellcome Trust and Children in Need, takes a different approach by exploring the role of science in youth club work outside schools to target and support young people from disadvantaged backgrounds. Importantly, the programme focuses on key outcomes such as strong self-belief, skills development, positive relationships and emotional wellness, rather than science aspirations in their own right. The pilot evaluation, involving 32 different repeatedintervention projects over several months across the UK, noted not only significant reported changes in these outcomes but also had unexpected positive outcomes, which included science-related career aspirations (Bright Purpose, 2019). The full-scale programme is currently under way and includes, for example, a programme by youth organizations People Know How and Science Ceilidh in Edinburgh, building on their pilot by running up to 30 youth club sessions annually with the same small group of 'at-risk' young people over three years. As well as focusing on supporting confidence, the programme will aim to capture changes in views about science and relationships, and determine any potential positive impacts on the young people's transition from primary to high school.

Finally, a number of protracted programmes for secondary and sixth-form students to experience undertaking cutting-edge scientific research have emerged in recent years. These have the potential to address the disconnect between science education and what professional scientists actually do (Braund and Reiss, 2006; Yeoman et al., 2017), which may have a role to play in raising, maintaining or confirming students' aspirations towards STEM subjects (L. Archer et al., 2020; M.O. Archer et al., 2020). Unfortunately, such programmes are rare globally, with those that do exist often lacking active support from researchers and/or targeting of disadvantaged groups (Bennett et al., 2018; M.O. Archer, 2020). One example which avoids both of these 
issues is the PRiSE (Physics Research in School Environments, www.qmul.ac.uk/spa/ researchinschools) programme at Queen Mary University of London - a scalable framework for six-month-long independent research projects based on current physics research topics. PRiSE is supported throughout by active researchers and has equitably involved diverse groups of 14-18-year-old London students (M.O. Archer, 2020; M.O. Archer et al., 2020). While in some regards this may be seen as similar to the short series, since each project only has a limited number of interventions between researchers and students, the key difference is that there is significant activity between these interventions where students and their teachers work on these research projects. Therefore, the interventions can be thought of as more of a support mechanism for a wider programme, empowering the students to complete their investigations and present them at dedicated student conferences to other PRiSE students, teachers, peers, family and friends. Longitudinal evaluation (M.O. Archer and DeWitt, 2020) at the six-month and three-year stages has shown lasting effects on students' STEMrelated confidence and skills. Furthermore, there is evidence suggesting participating students are more likely to continue with physics than beforehand (and, to some extent, STEM more broadly) as a direct result, with longitudinal evidence three years later also revealing greater uptake (to a statistically significant level despite the small sample size) from PRiSE students of both physics and STEM subjects at university than would be expected of physics students nationally. Beyond simply supporting students, PRiSE has been developing teachers' professional practice, and even affecting the profile of STEM across their schools (M.O. Archer and DeWitt, 2020). These wider impacts are further reinforced by the significant repeated buy-in from participating schools over several years (M.O. Archer, 2020).

All these programmes share a number of characteristics that are likely to contribute to their impacts. They are long term - over the course of a school year or more. They involve frequent and repeated activities which students encounter as part of their ordinary classroom learning experience. They both work with and support key influencers in the students' lives, for example, teachers are leading regular activities. The activities of the interventions are closely integrated with the curriculum in terms of subject content and skills development. They also link together different facets of learners' experience, both inside and outside the classroom. In understanding, however, how these different aspects contribute to impact upon students, we need to consider the wider picture, rather than simply the programmes themselves.

\section{The big picture}

While it appears that long-term interventions have the ability to measurably influence young people's aspirations and identification with science, such efforts are beyond the scope of many organizations. Such repeated interventions are also challenging to develop, deliver and maintain in settings outside school, simply because young people generally are not required to be there in the same way that school attendance is mandatory. Thus, it becomes important to consider how to maximize potential impacts of the many activities that can and do take place in formal and informal settings: one-offs, short series or even deeper programmes of engagement. This is where the notion of learning ecosystems or ecologies can be helpful (for example, Brofenbrenner, 1979). A learning ecology is the context (physical, social, cultural) in which learning takes place. Ecological perspectives on learning acknowledge that young people (and adults, for that matter) learn across a range of contexts, as well as over time, and all of this is influenced in a complex way by previous experiences, 
background factors, and what follows any given experience. An example diagram of a learning ecology model is shown in Figure 1, where the individual lies at the centre and the layers surrounding have decreasing amounts of direct interaction/influence with them. Such models serve to remind us that our interventions - whether one-offs, short series or longer, in whatever setting - do not operate in isolation. Moreover, they can be more powerful as learning experiences by linking to other elements in the learning ecosystem. That is, by making a conscious and concerted effort to form links among organizations, young people may be guided towards other experiences that reinforce what they have learned in our activities (Bevan, 2016; Traphagen and Traill, 2014). Doing so can also help us refine our efforts - define our niche - so that they better fit what is needed. In the United States, such initiatives are gaining momentum - and, indeed, a STEM Funders Network has formed to support such efforts in a concerted way (https:// stemecosystems.org/about-the-stem-funders-network/).

It is perhaps tempting for organizations that want to effect behaviour or aspiration change to develop an intervention that is based on 'common sense', but without considering the learning ecology that the child or young person is situated within, without identifying a realistic way in which the desired change could be achieved by the intervention, and with no research base underpinning the intervention. One way to overcome this temptation is to use a theory of change approach. This was initially

Figure 1: The learning ecology model of Brofenbrenner (1979), adapted by lan Joslin (from Laff and Ruiz, 2019)

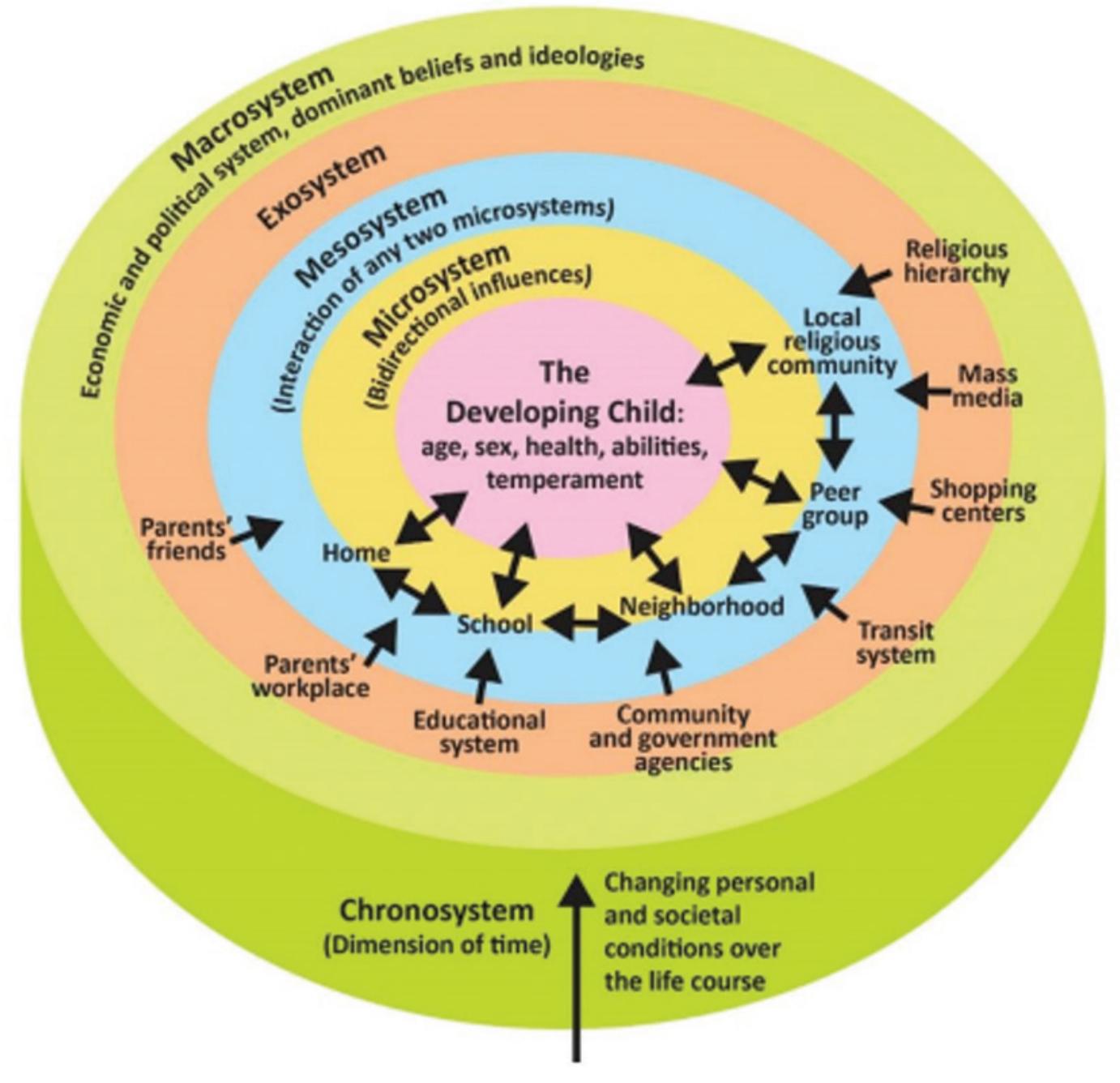


developed to evaluate complex initiatives (Sullivan and Stewart, 2006) and support long-term behaviour change. A key benefit of using a theory of change is that it starts with the end goal, and then requires the identification of intermediate outcomes through a process of backwards mapping that will, over time, lead to that goal. In this way, causal chains can be identified that link an intervention with evidence-based steps that should eventually lead to the desired change (Davenport et al., 2020). This process is an iterative one, and allows the production of a theory of change diagram, such as that shown in Figure 2, which depicts the changes involved in achieving the goal of an intervention.

\section{Challenges to the sector}

The recent review by Robinson and Salvestrini (2020) concerning programmes of engagement with young people advocated for further research to disentangle their individual components in order to better understand the most impactful elements. However, this is perhaps too reductive an approach to developing engagement programmes, given the context of learning ecologies and theories of change for impacting on young people's STEM aspirations. Indeed, we have presented several examples demonstrating that the aims of our engagements require considerable effort beyond that which is generally possible at present, and even then they remain complicated and difficult to realize. Therefore, there are many challenges for the sector, even with the emergence of these deeper programmes of engagement.

A common theme in many of the repeat interventions programmes discussed is the difficulty in evaluating what impacts, particularly on STEM aspirations, the interventions are having. Often, changes may be subtle, and without the right types of quantitative and/or qualitative analysis, it can appear as if no impact is occurring. Furthermore, longitudinal data are inherently difficult to obtain, and the few examples mentioned have had rather small sample sizes. Within universities the growing adoption of the Higher Education Access Tracker (HEAT, https://heat. ac.uk/) may help in this regard; however, this alone is not sufficient. For example, HEAT cannot demonstrate a causal link between interventions and outcomes; also, it does not provide a broader picture of the young person's entire learning ecology, that is, what other interventions they have also accessed. These pose real challenges to the engagement sector, especially with the current focus on evaluating what impact specific projects have had, such as through Research Excellence Framework (REF) Impact Case Studies (NCCPE, 2017).

The theory of change shown in Figure 2 identifies three groups of stakeholders that are key to increasing the number of young people choosing a STEM career: families, teachers (schools), as well as the children and young people themselves. However, it is noticeable that there is another set of stakeholder groups that does not appear on the diagram: companies, industrial sector bodies and other STEM organizations. Realistically, there is another theory of change that should be developed to explore the organizational changes that need to take place within companies to make them appealing places to work, and address the retention issues that mean a (not insignificant) proportion of young people who enter the STEM workforce do not remain there (Smith and White, 2019). The STEM engagement sector (including university outreach organizations) can be seen as 'working' indirectly for these additional stakeholders and doing some of their pre-recruitment work for them. This could lead to a certain moral ambiguity, if young people are being encouraged to enter sectors that are (still) not always welcoming to them. 


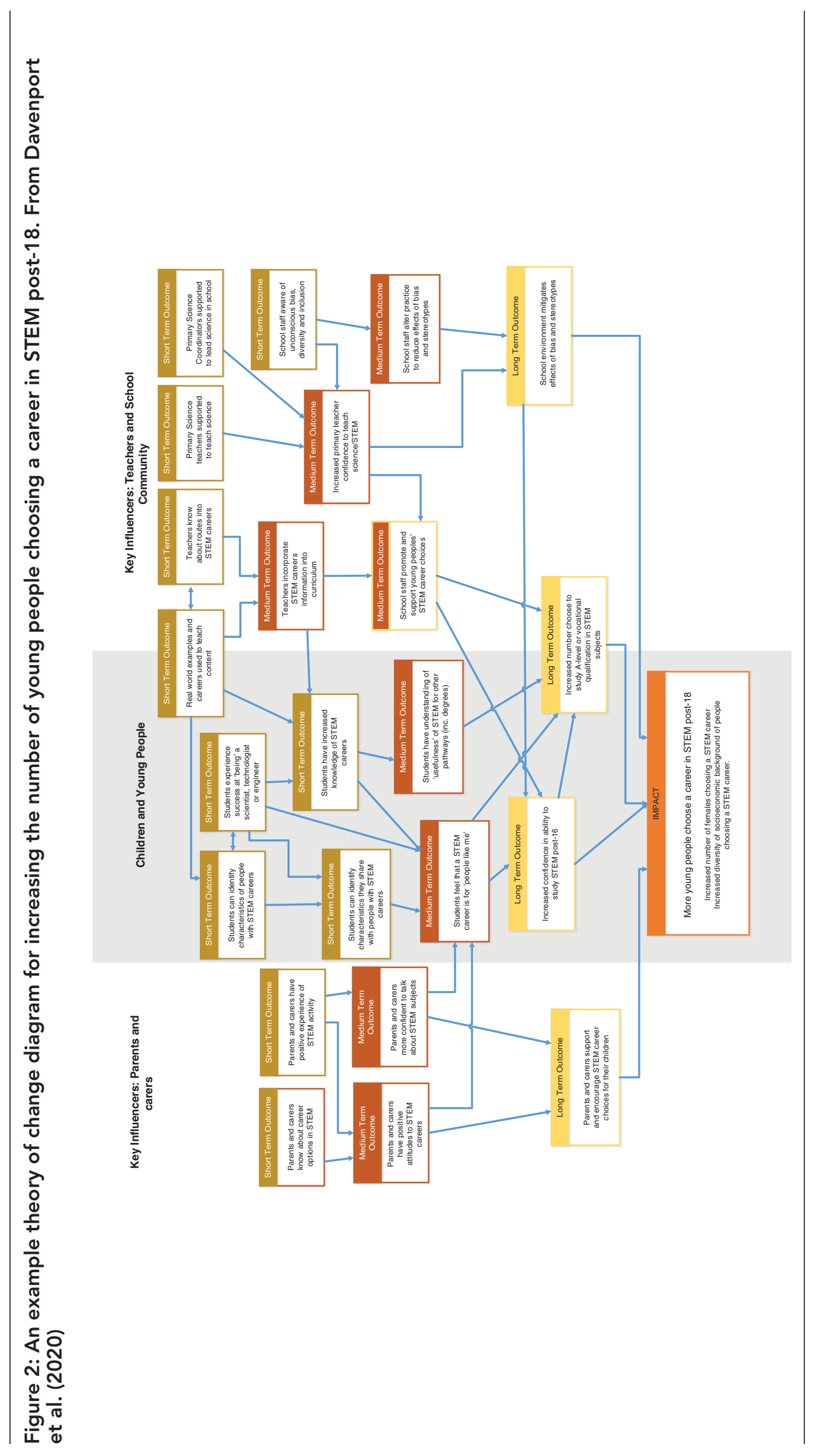


Another issue that is salient in the theory of change in Figure 2 is that the learning ecology is extremely challenging to effect. Many of the interventions in STEM engagement continue to focus on the young person, particularly around the points of 'choice' between GCSEs and A levels. Given the relatively short-term nature of industrial and academic planning, where five years is considered long term, this is not surprising. There has been some shift in age downwards, with recommendations for organizations to work in primary schools albeit at the upper end of the age range (HEFCE and OFFA, 2013). However, while some interventions involve teachers, very few include parents or carers. In many respects, this is understandable; parents of teenagers can be difficult to involve, particularly as some young people may resist some forms of parental involvement in their education (Deslandes and Cloutier, 2002). As young people progress through the education system, it becomes more likely that parents and carers will work during the day, and have limited capacity to attend evening events. There has not been, as yet, concerted sector-wide effort to identify how best to engage and include parents in STEM engagement, although programmes such as the Wellcome Trust and Children in Need's youth-work-based Curiosity, the Association for Science and Discovery Centre's community/family-based Explore Your Universe Phase 4 (www.sciencecentres.org.uk/projects/explore-your-universe/phase-4/) that is funded by the Science and Technology Facilities Council (STFC), and the Scottish Government's STEM Strategy (2017) focus on community learning and development show steps in this direction.

It is clear that different aims, messages and activities are needed as students progress through their education. Figure 3 shows a potential way of characterizing these throughout their educational journey. However, this raises questions as to who is best placed to be delivering these evolving messages. For example, it is arguable that a university academic is perhaps not the most effective person in discussing (or being a suitable role model for) the wealth of careers beyond academia that continued STEM education can provide. Similarly, many science communicators and engagement professionals do not have the depth of research knowledge or expertise that might be able to sustain a young person's interest through involving students in cutting-edge STEM. This highlights that we need to work more collaboratively, forming partnerships across all those who engage young people, in order to identify who is best placed to deliver the very different types of engagement necessitated at the various points along a young person's educational journey. Such wider collaborative working could, hopefully, shift the focus away from solely the impacts that individual programmes/organizations are having on STEM aspirations, and rather

\section{Figure 3: Diagram summarizing the educational journey of a child, their key influencers, and the changing nature of activities required during that time. From Davenport et al. (2020)}

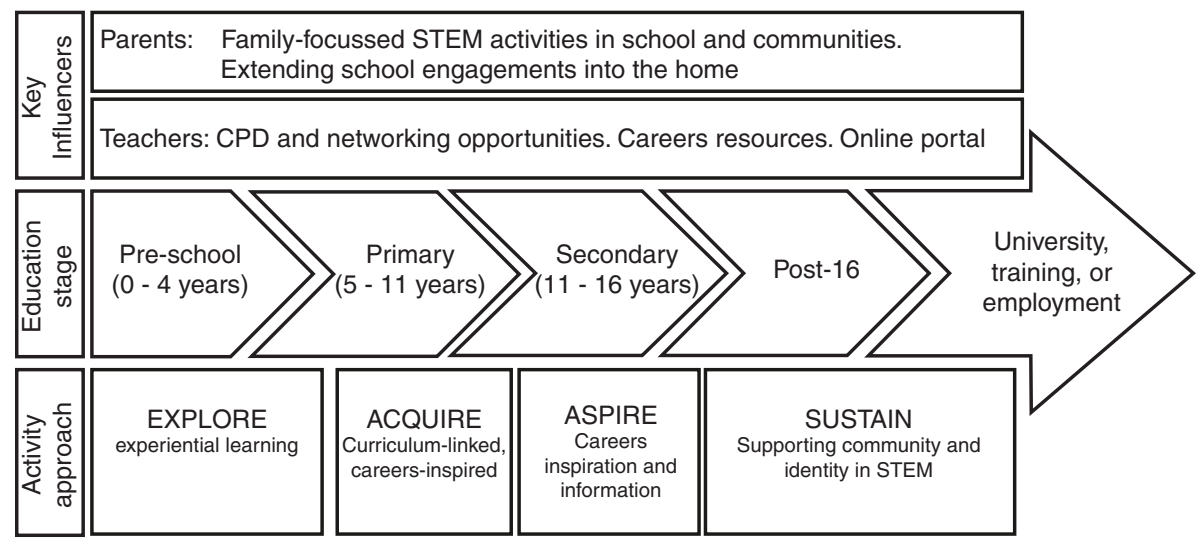


promote thinking about how (via theories of change and improved evaluations) we can collectively have positive impacts upon young people's learning ecologies.

Wider collaboration, however, comes with practical challenges on who should be managing, coordinating, resourcing and owning the STEM engagement space. It also comes with data sharing and protection issues regarding the evaluation of the entire learning ecology, rather than simply individual interventions or programmes. It is not currently clear how wide this might need to go. We have presented examples from networks of university departments (for example, the South East Physics Network) which still suffer from these sector-wide challenges, but whether that means that individual learned societies representing specific STEM subjects, UK Research and Innovation (UKRI) as the umbrella of the UK research councils, or indeed the government's Department for Education (DfE) need to step up and take ownership of this mission is up for debate. In Scotland, the Scottish Public Engagement Network (ScotPEN, www.scotpen.org/) is beginning to develop a broader network model across universities, learned societies and other informal science organizations, and is working strategically, including locally distributing public engagement funding for Wellcome Trust-funded researchers along with working groups to support more impactful work across the ecology.

The UK more widely could also draw upon models from other countries. For example, in the USA there exists the aforementioned STEM Funders Network, along with the Center for Advancement of Informal Science Education (CAISE, www. informalscience.org/) - a resource centre funded by the National Science Foundation designed to support and connect the informal STEM education community in museums, media, public programmes and a growing variety of learning environments. Similar public engagement networks exist across Europe, such as Wissenschaft Im Dialog (Science in Dialogue) and Vetenskap \& Allmänhet (VA: Public \& Science), which aim to strategically support public engagement across stakeholders, including universities, learned societies, funders and other informal science organizations across Germany and Sweden respectively.

\section{Conclusions}

Raising and maintaining STEM aspirations are a typical aim of universities' and other practitioners' and organizations' engagements with young people. Aspirations are, however, incredibly complex and difficult to effect, so it is not surprising that any single one-off intervention in isolation, while able to achieve a number of worthy positive outcomes, is unlikely to fundamentally change a young person's future trajectory. We have presented a landscape review and commentary of different emerging programmes of repeated STEM interventions with young people which therefore aim to maximize the likelihood of raising and supporting young people's STEM aspirations. While short series of interventions seem to suffer some of the same limitations as one-offs at present, there is emerging evidence that deeper programmes over the course of months to years that interact not only with the young person but also with key components within their wider learning ecology are able to measurably impact on STEM aspirations. However, there is no one-size-fits-all solution to raising and subsequently maintaining the STEM pipeline, and a variety of different approaches are required throughout a young person's educational journey.

While we believe that having more, deeper programmes of STEM engagement would be the most effective way of positively affecting the STEM landscape overall, we realize that this may not be possible for all types of informal STEM engagement 
practitioners and organizations. One-offs do have inherent value, however, and they might, within the wider learning ecology, be able to collectively contribute towards building and maintaining aspirations through various interventions, so long as they present coherent messages that reinforce one another. Programmes of repeated interventions may simply enable providers to control that longer-term messaging, giving individual providers more influence in a consistent way over a longer stretch of time than would otherwise be possible. They also inherently allow a greater ability to capture the impacts that the interventions have had. Nonetheless, we advocate that those who develop any STEM engagement activities or programmes consider adopting a theory of change approach to critically consider whether what they deliver, be they protracted programmes or one-offs, is likely to achieve (or even just contribute towards) the intended aims. Furthermore, we urge organizations where possible to try to involve and influence the wider ecology in an audience-focused way, with every activity to increase the likelihood of any impacts lasting. In lieu of a more joined-up collaborative approach across the entire sector, these considerations at the very least should help us all to make more of a difference.

\section{Notes on the contributors}

Martin Archer is a UKRI Stephen Hawking Fellow in space physics and public engagement at Imperial College London. He has been a leader in developing awardwinning innovative and impactful research-based outreach and public engagement activities for over a decade, sharing the excitement and importance of physics in accessible ways to a variety of often underserved audiences.

Jennifer DeWitt is a senior research fellow at the UCL Institute of Education, where she is a member of the team developing and applying the concept of science capital. She is also a research and evaluation consultant, specializing in science learning and engagement, with particular interests in learning in informal settings, including the implications of science capital research for equitable practice in these settings.

Carol Davenport is a senior lecturer and Director of NUSTEM at Northumbria University, Newcastle. Her research interests include the impact of STEM engagement activities on young people's career choices, the implementation of the Gatsby career benchmarks in subject classrooms and the effects of unconscious bias in primary schools.

Olivia Keenan is Director of Outreach and Public Engagement at the South East Physics Network (SEPnet). She leads the network's outreach programme and public engagement work. SEPnet work with schools to improve accessibility to, and uptake of, physics. They support their partner universities to engage diverse publics on the research they are conducting. Olivia is passionate about equality and representation in STEM, and she enjoys working on projects which help embed social justice by removing barriers to access.

Lorraine Coghill is Science Outreach Coordinator and North East Regional Representative for Durham University and the Ogden Trust. Lorraine creates, develops and cultivates opportunities for people to work together to explore, enquire and engage others. With nearly twenty years' engagement experience, she develops and manages creative and award-winning programmes, and is particularly passionate 
about training and supporting others in advancing their own engagement practice and confidence.

Anna Christodoulou is Collaborative Outreach Officer for Make Happen, the Uni Connect Partnership in Essex. She is working with schools, higher education and further education institutions and charities to raise aspirations and widen participation in higher education throughout Essex. She is a very experienced project manager, specializing in outreach and public engagement with research, and an awarded science communicator.

Samantha Durbin has been Clothworkers' Associate in Mathematics at the Royal Institution (Ri) since 2012, managing the Ri's Secondary Mathematics Masterclass network across the UK. She also co-organizes Talking Maths in Public, a skills sharing network and biennial conference for people working in mathematics outreach/ communication. Samantha was previously a STEM Clubs advisor at the British Science Association, having completed an MSc in science communication at the University of the West of England in 2012 and a master's of mathematics at the University of Bath in 2010.

Heather Campbell completed an MPhys in astrophysics with research placement at the University of Sussex in 2009, then a PhD on the explosions of stars, type la supernovae, to explore the accelerated expansion of the universe, at the University of Portsmouth. Heather worked as a postdoctoral researcher on the Gaia satellite at the University of Cambridge. For the last four years, Heather has been the SEPnet/Ogden Public Engagement and Outreach Manager at the University of Surrey.

Lewis Hou is an interdisciplinary education and cultural participation specialist. He is particularly interested in public and community engagement approaches that build meaningful and equitable relationships with diverse groups beyond the 'already converted', and he was the recipient of the Royal Society of Edinburgh's Public Engagement Innovator Medal in 2018. He founded and directs the Science Ceilidh, an education and community organization exploring curiosity, creativity, equity, and health and well-being with adults, youth groups and schools across Scotland.

\section{References}

Archer, L. and DeWitt, J. (2017) Understanding Young People's Science Aspirations: How students form ideas about 'becoming a scientist'. London: Routledge. https://doi.org/10.4324/ 9781315761077.

Archer, L., DeWitt, J. and Dillon, J. (2014) '“It didn't really change my opinion": Exploring what works, what doesn't and why in a school science, technology, engineering and mathematics careers intervention'. Research in Science \& Technological Education, 32 (1), 35-55. https://doi.org/10.1080/02635143.2013.865601.

Archer, L., Dawson, E., DeWitt, J., Seakins, A. and Wong, B. (2015) '“Science capital": A conceptual, methodological, and empirical argument for extending bourdieusian notions of capital beyond the arts'. Journal of Research in Science Teaching, 52 (7), 922-48. https://doi.org/10.1002/ tea.21227.

Archer, L., DeWitt, J. and King, H. (2018) 'Improving science participation: Five evidencebased recommendations for policy-makers and funders'. 22 May. London: UCL Institute of Education. Accessed 19 November 2020. https://ioelondonblog.wordpress.com/2018/05/22/ improving-science-participation-five-evidence-based-recommendations-for-policy-makersand-funders/. 
Archer, L., Moote, J. and MacLeod, E. (2020) 'Learning that physics is "not for me": Pedagogic work and the cultivation of habitus among advanced level physics students'. Journal of the Learning Sciences, 29 (3), 347-84. https://doi.org/10.1080/10508406.2019.1707679.

Archer, M.O. (2020) 'School students from all backgrounds can do physics research: On the accessibility and equity of the PRiSE approach to independent research project'. Geoscience Communication Discussions, https://doi.org/10.5194/gc-2020-37, in review.

Archer, M.O. and DeWitt, J. (2020) '"Thanks for helping me find my enthusiasm for physics!" The lasting impacts "research in schools" projects can have on students, teachers, and schools'. Geoscience Communication Discussions, https://doi.org/10.5194/gc-2020-36, in review.

Archer, M.O., DeWitt, J., Davenport, C. and Hou, L. (2019) 'Going beyond the one-off: Get with the programme'. Session at BIG Event 2019, Dynamic Earth, Edinburgh, UK. July. BIG STEM Communicators Network.

Archer, M.O., DeWitt, J. and Thorley, C. (2020) 'Transforming school students' aspirations into destinations through extended interaction with cutting-edge research: "Physics Research in School Environments"'. Geoscience Communication Discussions, https://doi.org/10.5194/gc-2020-35, in review.

Barmby, P., Jones, K., Kokotsaki, D., Ndaji, F., Searle, J. and Skinner, P. (2008) Evaluation of the Royal Institution Secondary Mathematics Masterclasses Programme: Summary report. CEM Centre, Durham University. Accessed 19 November 2020. www.rigb.org/docs/cem_summary_report_0. pdf.

Bell, P., Lewenstein, B., Shouse, A.W. and Feder, M.A. (eds) (2009) Learning Science in Informal Environments: People, places, and pursuits. Committee on Learning Science in Informal Environments, National Research Council. https://doi.org/10.17226/12190.

Bennett, J., Dunlop, L., Know, K.J., Reiss, M.J. and Torrance Jenkins, R. (2018) 'Practical independent research projects in science: A synthesis and evaluation of the evidence of impact on high school students'. International Journal of Science Education, 40 (14), 1755-73. https://doi.org/10.1080/09500693.2018.1511936.

Bevan, B. (2016) 'STEM learning ecologies: Relevant, responsive, and connected'. Connected Science Learning, 1, 1-11. http://csl.nsta.org/2016/03/stem-learning-ecologies/.

Bhattacharyya, S., Mead, T.P. and Nathaniel, R. (2011) 'The influence of science summer camp on African-American high school students' career choices'. School Science and Mathematics, 111, 345-53. https://doi.org/10.1111/j.1949-8594.2011.00097.x.

Braund, M. and Reiss, M. (2006) 'Towards a more authentic science curriculum: The contribution of out-of-school learning'. International Journal of Science Education, 28 (12), 1373-88. https://doi.org/10.1080/09500690500498419.

Bright Purpose (2019) The Role of Informal Science in Youth Work. Findings from Curiosity round one. Wellcome Trust and BBC Children In Need. Accessed 19 November 2020. https://wellcome. ac.uk/sites/default/files/role-informal-science-learning-youth-work.pdf.

Bronfenbrenner, U. (1979) The Ecology of Human Development: Experiments by nature and design. Cambridge, MA: Harvard University Press.

Davenport, C., Dele-Ajayi, O., Emembolu, I., Morton, R., Padwick, A., Portas, A., Sanderson, J., Shimwell, J., Stonehouse, J., Strachan, R., Wake, L., Wells, G. and Woodward, J. (2020) 'A theory of change for improving children's perceptions, aspirations and uptake of STEM careers'. Research in Science Education. https://doi.org/10.1007/s11165-019-09909-6.

Deslandes, R. and Cloutier, R. (2002) 'Adolescents' perception of parental involvement in schooling'. School Psychology International, 23 (2), 220-32. https://doi.org/10.1177/014303430 2023002919

Deslauriers, L., McCarty, L.S., Miller, K., Callaghan, K. and Kestin, G. (2019) 'Measuring actual learning versus feeling of learning in response to being actively engaged in the classroom'. Proceedings of the National Academy of Sciences, 116 (39), 19251-57. https://doi.org/10.1073/ pnas. 1821936116.

DeWitt, J. (2019) I'm a Scientist: Supporting science capital. Report. Accessed 19 November 2020. https://about.imascientist.org.uk/files/2019/11/IAS-Science-Capital-Main-Report-Sep-2019.pdf.

DeWitt, J. and Storksdieck, M. (2008) 'A short review of school field trips: Key findings from the past and implications for the future. Visitor Studies, 11 (2), 181-97. https://doi.org/10.1080/ 10645570802355562.

DeWitt, J., Archer, L. and Moote, J. (2019) '15/16-year-old students' reasons for choosing and not choosing physics at A level'. International Journal of Science and Mathematics Education, 17, 1071-87. https://doi.org/10.1007/s10763-018-9900-4.

Durham University Centre for Academic Development (2019) 'DCAD resource bank'. Accessed 7 February 2020. https://sites.durham.ac.uk/dcad-resourcebank/. 
Elkington, S. and Bligh, B. (2019) Future Learning Spaces: Space, technology and pedagogy. AdvanceHE. Accessed 7 February 2020. www.heacademy.ac.uk/system/files/downloads/ Future\%20Learning\%20Spaces_0.pdf.

Emembolu, I., Padwick, A., Shimwell, J., Sanderson, J., Davenport, C. and Strachan, R. (2020) 'Using action research to design and evaluate sustained and inclusive engagement to improve children's knowledge and perception of STEM careers'. International Journal of Science Education, 42 (5), 764-82. https://doi.org/10.1080/09500693.2020.1729442.

Freeman, S., Eddy, S.L., McDonough, M., Smith, M.K., Okoroafor, N., Jordt, H. and Wenderoth, M.P. (2014) 'Active learning increases student performance in science, engineering, and mathematics'. Proceedings of the National Academy of Sciences USA, 111 (23), 8410-15. https://doi.org/10.1073/ pnas.1319030111.

Gibbs, G. (2013) 'Lectures don't work, but we keep using them'. Times Higher Education. Accessed 7 February 2020. www.timeshighereducation.com/news/lectures-dont-work-but-we-keep-usingthem/2009141.article.

Godec, S., King, H., Archer, L., Dawson, E. and Seakins, A. (2018) 'Examining student engagement with science through a Bourdieusian notion of field'. Science \& Education, 27 (5-6), 501-21. https://doi.org/10.1007/s11191-018-9988-5.

Hamlyn, B., Shanahan, M., Lewis, H., O’Donoghue, E., Hanson, T. and Burchell, K. (2015) Factors Affecting Public Engagement by Researchers. TNS BMRB and Policy Studies Institute. Accessed 19 November 2020. https://wellcome.ac.uk/sites/default/files/wtp060033_0.pdf.

HEFCE and OFFA (Higher Education Funding Council for England and Office for Fair Access) (2013) National Strategy for Access and Student Sources: Interim report to the Department for Business, Innovation and Skills. London: HMSO.

Hope-Stone Research (2018) Connect Physics 2017-18 Evaluation Report. Technical report, SEPnet, October 2018. Accessed 23 November 2020. www.sepnet.ac.uk/wp-content/uploads/2018/09/ Connect-Physics-Complete-Evaluation-Report-2017-18.pdf.

IOP (Institute of Physics) (2013) Closing Doors: Exploring gender and subject choice in schools. Accessed 23 November 2020. https://d25f0oghafsja7.cloudfront.net/sites/default/files/2019-03/ closing-doors.pdf.

IOP (Institute of Physics) (2015) Opening Doors: A guide to good practice in countering gender stereotyping in schools. Accessed 23 November 2020. www.iop.org/sites/default/files/2019-02/ opening-doors-countering-stereotyping.pdf.

lowa State University's Center for Excellence in Teaching (2020) 'Effective lectures'. Accessed 7 February 2020. www.celt.iastate.edu/teaching/teaching-format/effective-lectures/.

Jeavans, E. and Jenkins, S. (2017) Shattering Stereotypes Pilot Project 2016/17: Final evaluation report. SEPnet. Accessed 19 November 2020. www.sepnet.ac.uk/wp-content/uploads/2018/02/ Shattering-Stereotypes-Pilot-Evaluation-Final-Report.pdf.

Laff, R. and Ruiz, W. (2019) Child, Family, and Community. College of the Canyons. Accessed 7 December 2020. https://socialsci.libretexts.org/Bookshelves/Early_Childhood_Education/ Book\%3A_Child_Family_and_Community_(Laff_and_Ruiz).

Maclver, M.A. and Maclver, D.J. (2015) The Baltimore City Schools Middle School STEM Summer Program with VEX Robotics. Baltimore Education Research Consortium. Accessed 19 November 2020. https://eric.ed.gov/?id=ED570654.

Marbach-Ad, G. and Sokolove, P.G. (2000) 'Can undergraduate biology students learn to ask higher level questions?'. Journal of Research in Science Teaching, 37 (8), 854-70. https://doi.org/10.1002/1098-2736(200010)37:8<854::AID-TEA6>3.0.CO;2-5.

Marbach-Ad, G., Claassen, L.A. (2001) 'Improving students' questions in inquiry labs'. The American Biology Teacher, 63 (6), 410-19. https://doi.org/10.1662/0002-7685(2001)063[0410:ISQIIL]2.0. $\mathrm{CO} ; 2$.

Monahan, T. (2002) 'Flexible space and built pedagogy: Emerging IT embodiments'. Inventio, 4 (1), 1-19. Accessed 19 November 2020. http://publicsurveillance.com/papers/built_pedagogy.pdf.

Murre, J.M.J. and Dros, J. (2015) 'Replication and analysis of Ebbinghaus' forgetting curve'. PLoS ONE, 10 (7), e0120644. https://doi.org/10.1371/journal.pone.0120644.

NCCPE (National Co-ordinating Centre for Public Engagement) (2017) Reviewing the REF Impact Case Studies and Templates. Accessed 19 November 2020. www.publicengagement.ac.uk/sites/ default/files/publication/nccpe_ref_review_executive_summary.pdf.

Robinson, D. and Salvestrini, V. (2020) The Impact of Interventions for Widening Access to Higher Education: A review of the evidence. TASO report. Accessed 19 November 2020. https://epi.org. uk/wp-content/uploads/2020/01/Widening_participation-review_EPI-TASO_2020.pdf. 
Royal Institution (2018) Ri Mathematics Masterclass Programme: Impact report for the Clothworkers' Foundation. Accessed 19 November 2020. www.rigb.org/docs/masterclasses_impact_report_ nov2018_0.pdf.

Scottish Government (2017) Science Technology Engineering Maths Education and Training Strategy for Scotland. Accessed 19 November 2020. www.gov.scot/binaries/content/ documents/govscot/publications/strategy-plan/2017/10/science-technology-engineeringmathematics-education-training-strategy-scotland/documents/00526536-pdf/00526536-pdf/ govscot\%3Adocument/00526536.pdf.

Shimwell, J., Davenport, C., Padwick, A., Sanderson, J. and Strachan, R. (under review) 'Scientist of the Week: The long-term effects of a medium-term, teacher-led STEM intervention to reduce stereotypical views of scientists in young children'.

Smith, A. (2004) Making Mathematics Count: The report of Professor Adrian Smith's inquiry into post-14 mathematics education. London: The Stationery Office.

Smith, E. and White, P. (2019) 'Where do all the STEM graduates go? Higher education, the labour market and career trajectories in the UK'. Journal of Science Education and Technology, 28, 26-40. https://doi.org/10.1007/s10956-018-9741-5.

Sullivan, H. and Stewart. M. (2006) 'Who owns the Theory of Change?'. Evaluation, 12 (2), 179-99. https://doi.org/10.1177/1356389006066971.

Traphagen, K. and Traill, S. (2014) How Cross-Sector Collaborations are Advancing STEM Learning. The Noyce Foundation. Accessed 19 November 2020. https://smile.oregonstate.edu/sites/smile. oregonstate.edu/files/stem_ecosystems_report_execsum_140128.pdf.

Thorley, C. (2016) 'Physicists and Outreach: Implications of schools physics outreach programmes from the perspective of the participating physicists'. EdD thesis, UCL Institute of Education, London. Accessed 19 November 2020. https://discovery.ucl.ac.uk/id/eprint/1503745.

Universify Education (n.d.) 'Our impact'. Accessed 23 November 2020. www.universifyeducation. com/impact.

Weinstein, M., Whitesell, E.R. and Schwartz, A.E. (2014) 'Museums, zoos, and gardens: How formalinformal partnerships can impact urban students' performance in science'. Evaluation Review, 38 (6), 514-45. https://doi.org/10.1177/0193841X14553299.

Woods-Townsend, K., Christodoulou, A., Rietdijk, W., Byrne, J., Griffiths, J. and Grace, M. (2016) 'Meet the scientist: The value of short interactions between scientists and students'. International Journal of Science Education Part B, 6 (1), 89-113. https://doi.org/10.1080/215484 55.2015 .1016134

Yeoman, K., Nardi, E., Bowater, L. and Nguyen, H. (2017) '"Just Google it?": Pupils' perceptions and experience of research in the secondary classroom'. British Journal of Educational Studies, 65 (3), 281-305. https://doi.org/10.1080/00071005.2017.1310179. 